\title{
Questionnaire Survey of Metal Plate Construction
}

\author{
by \\ Yoshinori SATO, Toshiki ICHIWATA, Junji TSUKUI, Keiichi ISHIGAMI, \\ Shigeyuki KASAI, Koichiro UEDA, Tomotaka TAKEDA, \\ Masayuki SHIRANE, Hiromi GOTO, Toshikazu IBONAI, \\ Akihisa NAKAMURA, Eiichi MORITA and Katsuzo OHKI
}

\section{Introduction}

Metal plates are available as cast plates or swaged plates [1]. At present, swaged plates are not much used, and cast plates are used in most cases. The construction of a cast plate $[2,3]$ requires a number of machines, and the material and technical processes are complex [4-6]. In Japan, the construction of metal plates for patients attending private dental clinics is entrusted to private laboratories. At the Nihon University Dental Hospital, metal plates for patients are made at a metal plate laboratory within the hospital itself. The number of plates made at this laboratory ranges from 100 to 150 a year.

Accordingly, we conducted a questionnaire survey of 98 private metal plate laboratories in all parts of Japan, in order to assess the existing state of metal-plate construction. Thirty-four laboratories responded, and their answers are analyzed and reported on in this paper.

\section{Survey Method}

Questionnaires were sent to 98 private metal-plate laboratories which are members of a Trade Association formed by their operators, and the questions referred to metal plates constructed during 1982. Thirty-four laboratories replied, and these replies were analyzed. The survey was in two parts, one covering general subjects and the other methods of construction. Incidentally, differences in the numbers of answers arise from the fact that no answers were given to certain questions by certain respondents.

\section{Results}

1. General Subjects

1) Number of Metal Plates Constructed

The relationship between the number of metal plates constructed, including full and partial plates, and the number of laboratories which made them, is shown in Table 1 and Figs. 1 and 2. As can be seen in Fig. 2, the percentage of laboratories making less than 1,000 plates a year was the highest at $47.8 \%$. The largest number of plates constructed at any one laboratory was 12,600 .

佐藤吉則, 一和多寿樹, 津久井淳人, 石上恵一, 葛西茂之, 植田耕一郎, 武田友孝, 白根雅之, 後藤 ひろみ, 伊保内利一, 中村昭久, 森田栄一, 大木一三: Dept. of Removable Partial Denture Prosthodontics, Niohn University School of Dentistry, Tokyo. 


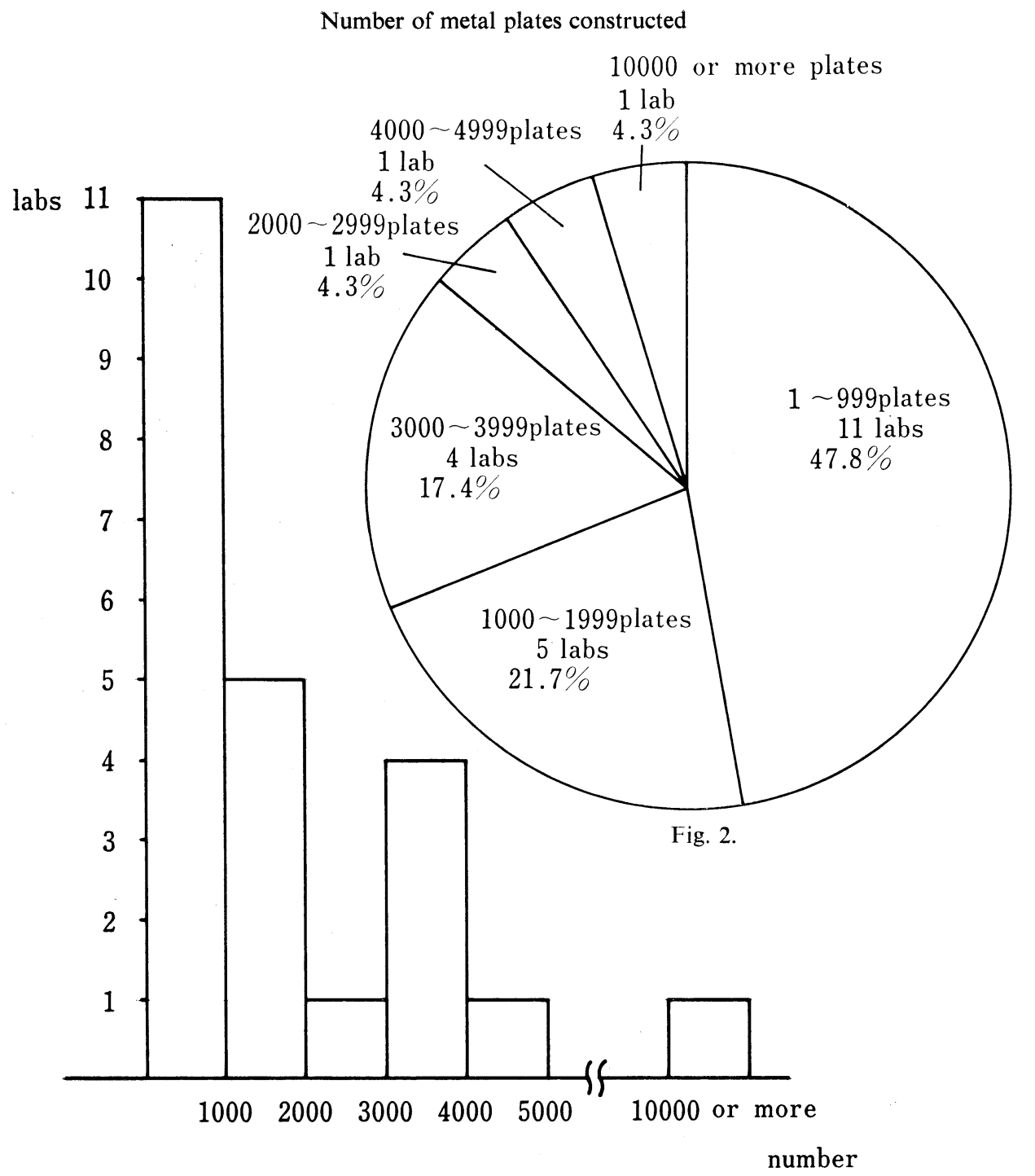

Fig. 1.

Table 1

\begin{tabular}{cc}
\hline Number constructed & Number of cases \\
\hline $1 \sim 999$ & 11 \\
$1000 \sim 1999$ & 5 \\
$2000 \sim 2999$ & 1 \\
$3000 \sim 3999$ & 4 \\
$4000 \sim 5000$ & 1 \\
10000 or more & 1 \\
\hline
\end{tabular}


Number of full metal plates constructed

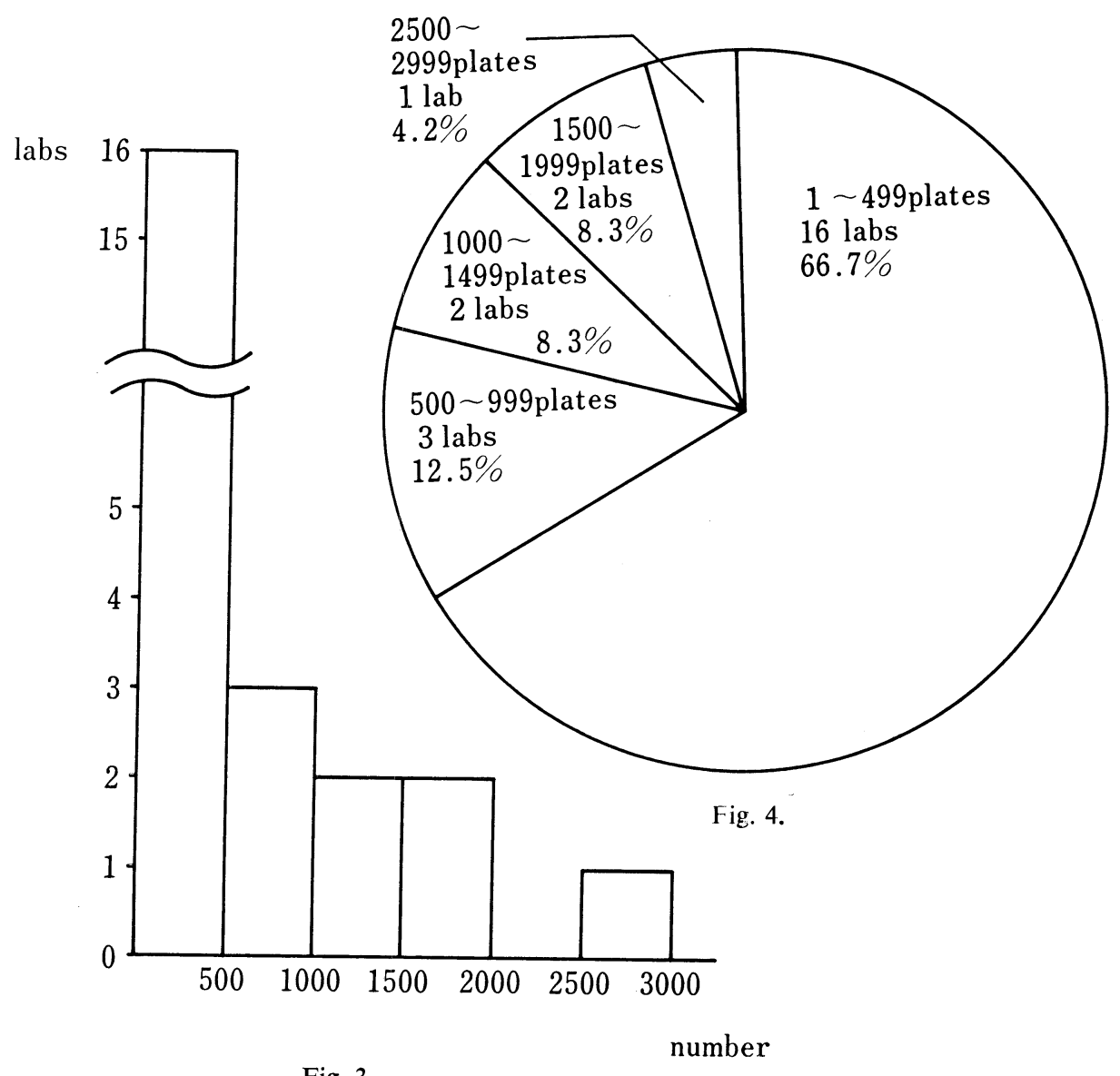

Fig. 3.

Table 2

\begin{tabular}{cc}
\hline Number constructed & Number of cases \\
\hline $100 \sim 499$ & 16 \\
500 & $\sim 999$ \\
$1000 \sim 1499$ & 2 \\
$1500 \sim 1999$ & 2 \\
$2000 \sim 2499$ & 0 \\
$2500 \sim 3000$ & 1 \\
\hline
\end{tabular}


Number of partial metal plates constructed

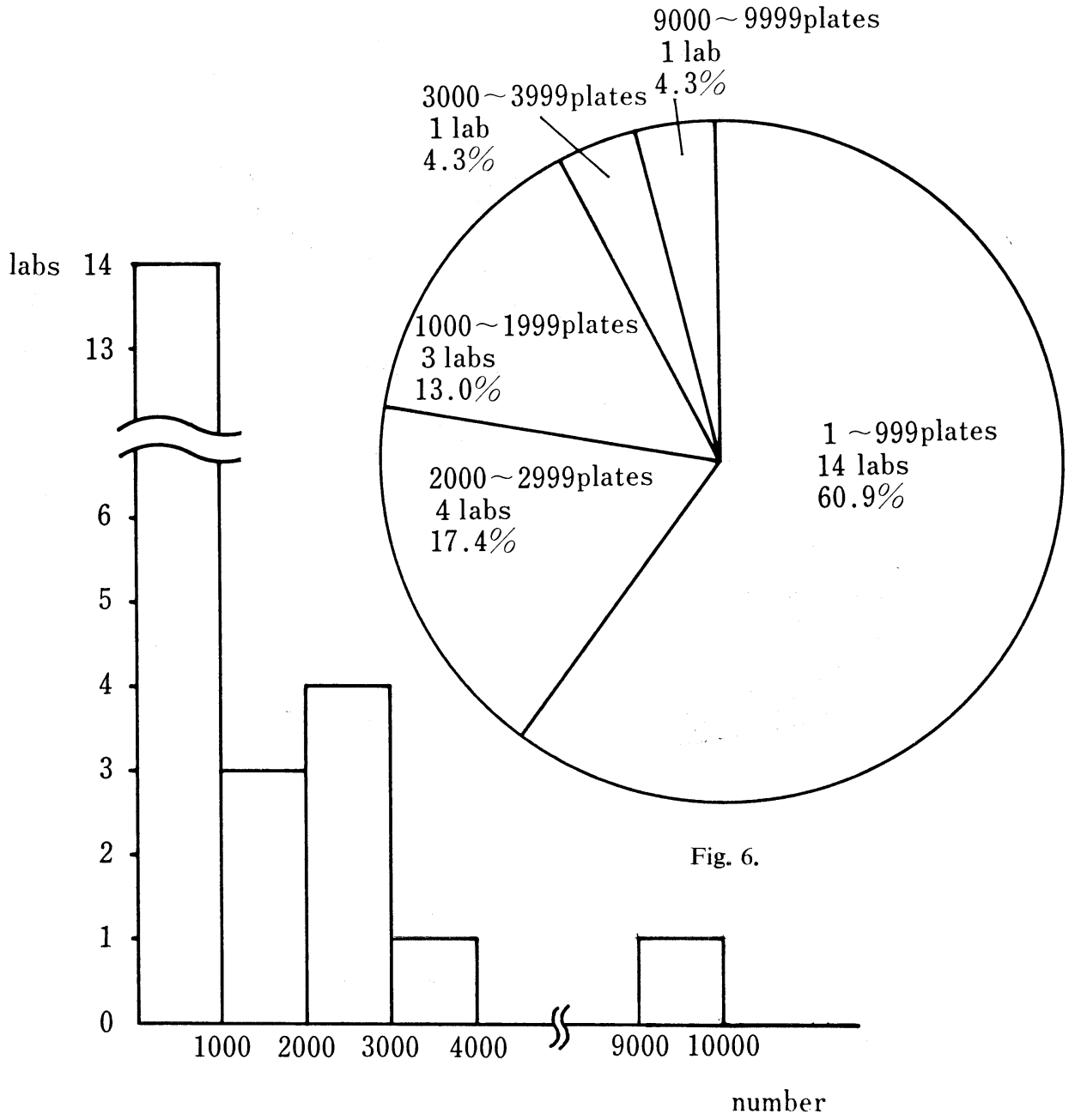

Fig. 5.

Table 3

\begin{tabular}{cc}
\hline Number constructed & Number of cases \\
\hline $1 \sim 999$ & 14 \\
$1000 \sim 1999$ & 3 \\
$2000 \sim 2999$ & 4 \\
$3000 \sim 3999$ & 1 \\
$9000 \sim 10000$ & 1 \\
\hline
\end{tabular}


Ratio of number of partial metal plates to total

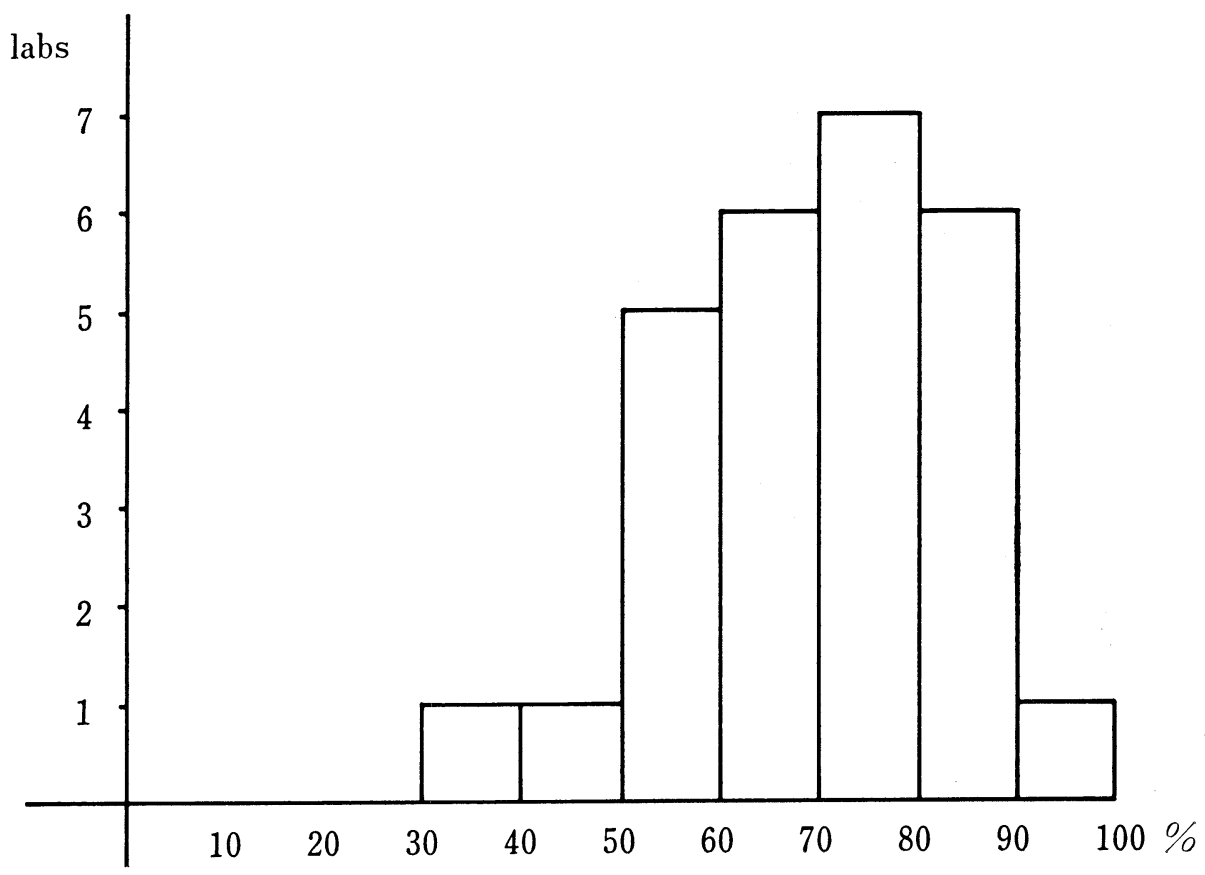

Fig. 7.

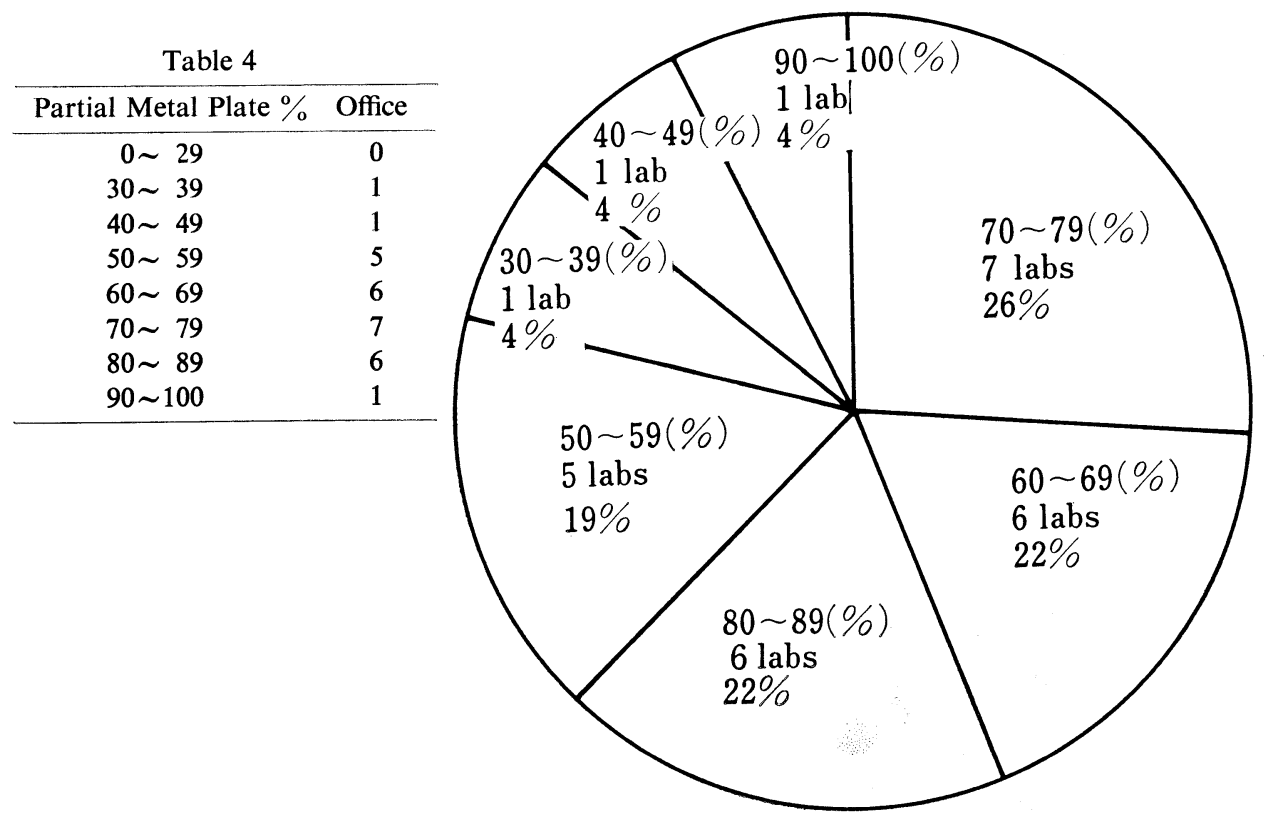

Fig. 8. 


\section{2) Full Metal Plates}

The relationship between the number of full metal plates constructed and the number of laboratories which made them, is shown in Table 2 and Figs. 3 and 4. As can be seen in Fig. 4, the percentage of laboratories making less than 500 a year was the largest at $66.7 \%$.

3) Partial Metal Plates

The relationship between the number of partial metal plates constructed and the number of laboratories which made them is shown in Table 3 and Figs. 5 and 6. As can be seen in Fig. 6, the percentage of laboratories making less than 1,000 a year was the largest at $60.9 \%$.

4) Ratio of Partial Metal Plates to Total

The ratio of the number of partial metal plates constructed in the year at the various laboratories against the total number of metal plates constructed is given in Table 4 and Figs. 7 and 8. As can be seen in Table 4, partial metal plates accounted for more than $50 \%$ at 25 laboratories, and for less than $50 \%$ only at 2 laboratories. This means that partial plates account for more than $50 \%$ of the total at most laboratories.

2. Methods of Consturction

1) Ventilation Provided for Laboratories

Provided: $100 \% \quad$ Not provided: $0 \%$

2) Implements and Materials Used

Use one company's system only: $38 \%$ (13 labs.)

Use various companies' systems: $62 \%$ (21 labs.)

3) Type of Surveyor Used

Ney's products: $77 \% \quad$ Other products: $23 \%$

4) Most Frequently-Used Clasps

(1) Maxilla

(i) Kennedy class I and II

I-bar clasp: $44 \% \quad$ Aker's clasp: $33 \% \quad$ Others: $23 \%$

(ii) Kennedy class III

Aker's clasp: $91 \% \quad$ I-bar clasp: $6 \% \quad$ Others: $3 \%$

(2) Mandible

(i) Kennedy class I and II

I- bar clasp: $61 \% \quad$ Aker's clasp: $26 \% \quad$ Others: $13 \%$

5) Is Attachment Done?

Yes: $91 \%$ (31 labs.) No: $9 \%$ (3 labs.)

6) Are Swaged Metal Plates Made?

Yes: $21 \%$ (7 labs.) No: $79 \%$ (27 labs.)

7) Are Crowns and Bridges Made?

Yes: $88 \%$ (30 labs.) No: 12\% (4 labs.)

8) Metals Used for Cast Plates

(1) Co-Cr alloy only: $37 \%$

(2) $\mathrm{Ni}-\mathrm{Cr}$ alloy only: $9 \%$

(3) $\mathrm{Co}-\mathrm{Cr}$ and $\mathrm{Ni}-\mathrm{Cr}$ alloys: $3 \%$

(4) Au alloy, $\mathrm{Co}-\mathrm{Cr}$ and Ni-Cr alloys: $51 \%$ 
9) Average Number of Days Required for Construction

(1) Full plate: 4.0 days

(2) Partial plate: 4.3 days

10) Prices (Average for 34 labs.)
(1) Full plate
$¥ 34,000$
(2) Partial plate
42,300
Co-Cr alloy
$¥ 20,700$
27,400

Au alloy

11) Duplicate Impression
(1) Flask material
Metal: $80 \% \quad$ Plastic: $11 \% \quad$ Others: $9 \%$

(2) To what degree is hydro-colloid impression-material used?

(i) Number of plates
Up to 30 plates: $75 \%$
31 to 60 plates: $5 \%$
60 plates or more: $20 \%$

(ii) Number of days

10 days or less: $46 \%$

21 to 30 days: $29 \%$

11 to 20 days: $21 \%$

More than 30 days: $4 \%$

(3) Bases for judging the limit of the use of hydro-colloid impression-material

Elasticity change: $54 \% \quad$ Color-tone change: $14 \%$

From experience: $11 \% \quad$ Others: $21 \%$

(4) Fluid temperature of hydro-colloid impression-material
$39-40{ }^{\circ} \mathrm{C}: 15 \%$
$41-45^{\circ} \mathrm{C}: 15 \%$
$51-55^{\circ} \mathrm{C}: 32 \%$
$46-50{ }^{\circ} \mathrm{C}: 29 \%$
$56-58^{\circ} \mathrm{C}: 9 \%$

(5) Cooling methods for hydro-colloid impression-material

(i) Natural cooling and water cooling: $71 \%$

(ii) Natural cooling only: $12 \%$

(iii) Water cooling only: $17 \%$

12) Refractory Casts

(1) After pouring the refractory material into the hydro-colloid material, how many minutes are allowed before it is taken out?

40 minutes or less: $48 \% \quad 41-80$ minutes: $48 \%$

81 minutes or more: $4 \%$

(2) Type of coating material for refractory cast

13) Waxing
Wax bath: $53 \%$
Spray: $11 \%$
Others: $36 \%$
(1) Use of stipple wax
For maxilla only: $76 \%$
For maxilla and mandible: $21 \%$
Not used: $3 \%$
(2) Fixing of finish-line position
Under doctor's instruction: $14 \%$
Fixed by laboratory: $86 \%$


(3) Resin plate retention form

Mesh form: $23 \%$

14) Investing

Letter V form: $3 \%$

Loop form: $15 \%$

Others: $59 \%$

(1) Number of sprues

$\begin{array}{lrcc} & \text { Mean } & \text { Max } & \text { Min } \\ \text { Maxilla } & 2.4 & 6 & 1 \\ \text { Mandible } & 2.0 & 5 & 1\end{array}$

(2) Casting ring

Ring used: $15 \%$

Ringless: $85 \%$

Plastic: $67 \%$

Metal: $27 \%$

Rubber: $3 \%$

Others: $3 \%$

(3) Investment material mixing Vacuum mixing: $73 \%$ Manual mixing: $27 \%$

(4) Burn-out period

After investing, within 1 hour: $9 \%$ about 1 hour: $18 \%$

more than 1 hour: $73 \%$

15) Casting Machines

(1) Metal melting method

High-frequency induction-heating furnace: $79 \%$

Arc furnace: $15 \% \quad$ Electric furnace: $3 \% \quad$ Others: $3 \%$

(2) Casting methods

Centrifugal method: $82 \% \quad$ Vacuum compression method: $8 \%$

Compression casting method: $8 \%$ Others: $2 \%$

(3) Casting machines

Horizontal high-frequency centrifugal machine: $79 \%$

Arc-compression casting machine: $16 \%$

Oxygen-acetylene melting centrifugal-casting machine: $5 \%$

16) Causes of Cast Plate Reconstruction

(1) Responsibility of doctors: $79 \%$

(2) Responsibility of laboratories: $21 \%$

Poor casts: $\begin{array}{r}78 \% \\ \text { Poor design: } \begin{array}{r}19 \% \\ \text { Others: }\end{array} \quad 3 \% \\ \text { Faulty casting: } 68 \% \\ \text { Poor design: } 21 \% \\ \text { Others: } \quad 11 \%\end{array}$

17) Fracture Points
(1) Clasp: $76 \%$
(2) Border between minor connector and plate: $16 \%$
(3) Bar of plate: $6 \%$
(4) Others: $2 \%$ 


\section{Summary}

The system used for cast-plate construction at the Nihon University Dental Hospital was developed by Shofu, Inc. (Japan). The duplicating hydro-colloid material, the hydro-colloid duplicating dispenser, the refractory cast material, the $\mathrm{Co}-\mathrm{Cr}$ alloy and the casting machines are all supplied by Shofu, Inc. While 100 to 150 cast plates are made a year, swaged metal plates are not made at all.

Cast plates used at the Hostipal, therefore, are limited in the method of construction, the number of plates and the system of application. Because of this, an assessment of the existing state of metal plate construction in the country was sought by means of a survey of dental laboratories since these make almost all the metal plates for patients attending private dental clinics.

Answers from 34 laboratories were analyzed and tabulated as below.

1. The percentage of laboratories making less than 999 metal plates a year was the highest at $47.8 \%$, and the highest number of plates made in a year at any one laboratory was 12,600 .

2. The percentage of laboratories making less than 500 full metal plates a year was $66.7 \%$ of the total, the highest.

3. The percentage of laboratories making less than 1,000 partial metal plates a year was $60.9 \%$ of the total, the highest.

4. The ratio of the number of partial metal plates to the total number of metal plates constructed a year at any one laboratory ranged from 70 to $79 \%$ at 7 laboratories or $27 \%$ of the total, the highest.

5. It was shown that a greater number of laboratories used implements and materials from various makers in constructing their metal plates rather than limiting their suppliers to a single maker.

\section{References}

[1] BouCHER, O.C. 1974. Current clinical dental terminology, C.V. Mosby, Saint Louis.

[2] Kawahara, H. et al. 1978. Dental cobalt-chromium alloy casting method, Ishiyaku-shuppan, Tokyo.

[3] HaSegawa, J. 1978. Dental Casting method, Ishiyaku-shuppan, Tokyo.

[4] Henderson, D. et al. 1977. McCracken's removalbe partial prosthodontics, C.V. Mosby, Saint Louis.

[5] RuDD, K.D. et al. 1981. Dental laboratory procedures, C.V. Mosby.

[6] StewART, K.L. et al. 1983. Clinical removable partial prosthodontics, C.V. Mosby.

[7] SАтон, Y. et al. 1982. Statistical observation of removable partial denture prostheses, J. Nihon Univ. S. D., 24, 95-101. 